\title{
Increased Vulnerability to Nicotine Self-Administration and Relapse in Alcohol-Naive Offspring of Rats Selectively Bred for High Alcohol Intake
}

\author{
A. D. Lê, ${ }^{1,2,3}$ Z. Li, ${ }^{1}$ D. Funk, ${ }^{1}$ M. Shram, ${ }^{1,2}$ T. K. Li $^{4}$ and Y. Shaham ${ }^{5}$ \\ ${ }^{1}$ Department of Neuroscience, Center for Addiction and Mental Health, Toronto, Ontario, Canada M5S 2S1, Departments of ${ }^{2}$ Pharmacology and ${ }^{3}$ Psychiatry, \\ University of Toronto, Toronto, Ontario, Canada M5S 1A8, ${ }^{4}$ Office of the Director, National Institute on Alcohol Abuse and Alcoholism-National Institutes of Health \\ (NIH)-Department of Health and Human Services, Bethesda, Maryland 20892, and ${ }^{5}$ Behavioral Neuroscience Branch, Intramural Research Program-National \\ Institute on Drug Abuse-NIH-Department of Health and Human Services, Baltimore, Maryland 21224
}

The prevalence of smoking in human alcoholics is substantially higher than in the general population, and results from twin studies suggest that a shared genetic vulnerability underlies alcohol and nicotine addiction. Here, we directly tested this hypothesis by examining nicotine-taking behavior in alcohol-naive offspring of alcohol-preferring $(\mathrm{P})$ rats and alcohol-nonpreferring $(\mathrm{NP})$ rats that had been selectively bred for high and low alcohol intake. The self-administration of intravenous nicotine $(0.015-0.060 \mathrm{mg} / \mathrm{kg}$ per infusion) in $\mathrm{P}$ rats was more than twice than that of NP rats. Nicotine seeking induced by reexposure to nicotine cues in extinction tests was also substantially greater in P rats than in NP rats. In a subsequent relapse test, priming nicotine injections reinstated drug seeking in $\mathrm{P}$ rats but not NP rats. P rats also self-administered higher amounts of oral sucrose (1-20\%) than NP rats, a finding consistent with previous reports. In contrast, self-administration of intravenous cocaine $(0.1875-1.125 \mathrm{mg} / \mathrm{kg}$ per infusion) was remarkably similar in the $\mathrm{P}$ and NP rats; however, P-NP differences in cocaine seeking emerged in subsequent extinction and cocaine priming-induced reinstatement tests. In both cases, lever responding was higher in P rats than in NP rats. Thus, alcohol-naive offspring of rats genetically selected for high alcohol intake are highly susceptible to nicotine self-administration and relapse, and this susceptibility is not likely caused by general reward deficits in NP rats. The present findings provide experimental evidence for the hypothesis that a shared genetic determinant accounts for the co-abuse of nicotine and alcohol.

Key words: extinction; genetic vulnerability; nicotine self-administration; P rats; NP rats; reinstatement; relapse

\section{Introduction}

Alcohol and nicotine are the two most frequently used drugs in the world, and they are often used together (Kandel et al., 1997). In humans, high correlations have been found between alcohol and nicotine use: the prevalence of smoking in alcoholics is approximately three times higher than in the general population (Istvan and Matarazzo, 1984; Kandel et al., 1997). Results from studies using laboratory rats are in agreement with these correlational data in humans (Soderpalm et al., 2000). For example, repeated treatment with nicotine increases home-cage intake and operant self-administration of alcohol (Lê et al., 2000; Olausson et al., 2001), and nicotine injections reinstate alcohol seeking in a rat model of relapse to drugs (Lê et al., 2003); however, although nicotine can potentiate alcohol-taking behavior, no studies have been published regarding the effect of alcohol exposure on nicotine-taking behavior.

Received April 1, 2005; revised Dec. 22, 2005; accepted Dec. 23, 2005

This work was supported by grants from the National Institute on Alcohol Abuse and Alcoholism. We thank Drs. D. Goldman and R. Tyndale for helpful comments on issues related to the genetics of alcohol and nicotine in humans.

Correspondence should be addressed to Dr. A. D. Lê, Department of Neurosciences, Center for Addiction and Mental Health, 33 Russell Street, Toronto, Ontario, Canada M5S2S1. E-mail: anh_le@camh.net. DOI:10.1523/JNEUROSCI.4895-05.2006

Copyright $\odot 2006$ Society for Neuroscience $\quad$ 0270-6474/06/261872-08\$15.00/0
Genetic factors are known to contribute to alcohol and nicotine use in humans (Tyndale, 2003). Twin studies have shown substantial genetic influences $(>50 \%)$ on both alcohol and nicotine addiction (Carmelli et al., 1992; Enoch and Goldman, 2001). Twin studies have also indicated that genetic factors may account for the co-abuse of nicotine and alcohol (Swan et al., 1997; Bierut et al., 2004; Goldman et al., 2005). For example, True et al. (1999) reported that the best-fitting model for the lifetime co-occurrence of nicotine and alcohol addiction includes a substantial genetic correlation between these disorders $(r=0.68)$. Results from studies using selective breeding of rats or mice for different effects of alcohol also demonstrate a substantial overlap between sensitivity to alcohol and sensitivity to nicotine. For example, mice or rats bred for increased responsiveness to the sedative effects of alcohol demonstrate increased sensitivities to nicotine-induced hypothermia and hypoactivity (De Fiebre et al., 1987). In another study, Gordon et al. (1993) examined alcoholpreferring $(\mathrm{P})$ rats and alcohol-nonpreferring $(\mathrm{NP})$ rats that were selectively bred for alcohol preference ( $\mathrm{Li}$ et al., 1993) and reported that the $\mathrm{P}$ rats were more sensitive to nicotine than the NP rats in a drug discrimination procedure.

The studies reviewed above and other similar reports have led to the hypothesis that shared genetic factors mediate the co-abuse 
of nicotine and alcohol (Tyndale, 2003); however, findings from human genetic studies are inconclusive, because comorbidity is common in many psychiatric disorders (Goldman et al., 2005; Krishnan, 2005) and because of the possibility that alcohol use leads to nicotine use or vice versa (Tyndale, 2003). Therefore, in our experiments, we tested the hypothesis that a shared genetic factor mediates vulnerability to both nicotine and alcohol by examining nicotine-taking behavior in alcohol-naive offspring of $\mathrm{P}$ and NP rats. We found that the P rats self-administered greater amounts of nicotine intravenously and demonstrated substantially more robust nicotine seeking induced by reexposure to cues associated with nicotine or to nicotine itself, as measured in extinction and drug priming-induced reinstatement tests.

\section{Materials and Methods \\ Subjects}

Fifteen male P rats and 15 male NP rats (30-45 d old) from the 44th generation (lines $\mathrm{iP}-10 \mathrm{~A}$ and $\mathrm{iNP}-4$ ) and 11 male P rats and 11 male NP rats (65-92 d old) from the 46th generation of the same lines were purchased from Indiana University Medical Center (Indianapolis, IN). The rats were quarantined for 2-6 weeks before the start of the experiments and were housed singly under a $12 \mathrm{~h}$ light/dark cycle (lights on at 7:00 A.M.). Water was available ad libitum throughout the experiment except for $1 \mathrm{~d}$ before training for sucrose self-administration. Food (Purina Rat Chow) was available ad libitum until the onset of drug selfadministration training. Subsequently, the rats were maintained on a restricted feeding of $20-22 \mathrm{~g} / \mathrm{d}$; food was given $1-2 \mathrm{~h}$ after the daily sessions. The experimental procedures followed the Principles of Laboratory Animal Care (NIH publication $85-23 ; 1996)$ and were approved by the local animal care committee.

\section{Surgery}

The rats were anesthetized with sodium pentobarbital $(55 \mathrm{mg} / \mathrm{kg}$, i.p.) and prepared surgically with SILASTIC catheters in the right jugular vein, as described previously (Corrigall and Coen, 1989). The catheter exited between the scapulas and was connected to a modified 22 gauge cannula. The rats were given an antibiotic treatment (Penlong, 30,000 U, i.m.; Rogar/STP, London, Ontario, Canada) immediately after surgery and were allowed 6-7 d to recover. The catheters were flushed daily with $0.1 \mathrm{ml}$ of a saline-heparin solution $(30 \mathrm{U} / \mathrm{ml})$.

\section{Apparatus}

Nicotine and cocaine self-administration were performed in eight chambers that were operated by a Med Associates (St. Albans, VT) interface system. Each chamber had two levers located $10 \mathrm{~cm}$ above the floor, but only one, the active lever (a retractable lever), activated the infusion pump (Razel Scientific Instruments, Stamford, CT) for $0.5 \mathrm{~s}$; presses on the inactive stationary lever were also recorded. The chambers were also equipped with a red house light and a white cue light that was located above the active lever. The modified 22 gauge cannula, attached to the intravenous catheter between the scapulas, was connected to fluid swivels (Lomir, Notre-Dame-de-L'Ile Perrot, Quebec, Canada) with PE-50 tubing that was protected by metal springs. The swivels were connected to 10 $\mathrm{ml}$ syringes attached to the infusion pumps.

Sucrose self-administration was conducted in a set of 16 operant conditioning boxes that were constructed locally. Each chamber was equipped with two stationary levers, which were symmetrically centered on one side panel $5 \mathrm{~cm}$ above the floor, a house light, and a cue light. A response on the active lever activated the infusion pump and turned on the cue light for $5 \mathrm{~s}$. Activation of the pump led to the delivery of $0.19 \mathrm{ml}$ of the sucrose solution to a liquid drop receptacle. Presses on the inactive lever had no programmed consequences.

\section{Drugs}

Cocaine (BDH Chemicals, Oakville, Ontario, Canada) and nicotine (Sigma, St. Louis, MO) solutions were prepared fresh daily with sterile saline vehicle (the $\mathrm{pH}$ was adjusted to 7.0 for the nicotine solutions). The unit doses for the intravenous nicotine self-administration (infusion volume of $25 \mu$ l over $0.5 \mathrm{~s}$ ) were $0.015,0.03$, and $0.06 \mathrm{mg} / \mathrm{kg}$ per infusion (all doses are expressed as the free base). Nicotine was also injected subcutaneously $(0.15 \mathrm{mg} / \mathrm{kg}$; injection volume, $1 \mathrm{ml} / \mathrm{kg})$ during the tests for reinstatement. The unit doses for intravenous cocaine selfadministration were $0.1875,0.375,0.75$, and $1.125 \mathrm{mg} / \mathrm{kg}$ per infusion. During reinstatement testing, cocaine ( 5 and $10 \mathrm{mg} / \mathrm{kg}$, i.p.) was injected in volume of $1 \mathrm{ml} / \mathrm{kg}$. The nicotine and cocaine doses for selfadministration and reinstatement are based on previous work (Corrigall and Coen, 1989; Shaham et al., 1997; Shoaib et al., 1997; Roberts and Brebner, 2000; Lu et al., 2004b).

\section{Procedures}

Experiment 1: Sucrose self-administration. The P and NP rats that subsequently underwent intravenous catheter surgery and were trained for intravenous nicotine and cocaine self-administration were initially trained to lever press for oral sucrose. In Experiment 1a, two groups of $\mathrm{P}$ and NP rats ( $n=15$ per line) were deprived of water for $24 \mathrm{~h}$ and then trained for $10 \mathrm{~d}(2 \mathrm{~h} / \mathrm{d}$ for the first $3 \mathrm{~d}$ and $1 \mathrm{~h} / \mathrm{d}$ for the last $6 \mathrm{~d})$ to press a lever for $10 \%$ oral sucrose $[0.19 \mathrm{ml}$ per reward delivery; fixed ratio-1 (FR-1) schedule; each lever press was reinforced]. We found P-NP differences for the intake of $10 \%$ oral sucrose. Therefore, in Experiment 1b, two other groups of $\mathrm{P}$ and NP rats $(n=11$ per line) were deprived of water for $24 \mathrm{~h}$ and then trained for $10 \mathrm{~d}(1 \mathrm{~h} / \mathrm{d})$ to press a lever for $10 \%$ oral sucrose. Subsequently we determined lever responding for different sucrose concentrations $(1,3$, and $20 \%)$ in three counterbalanced sessions that were performed $3 \mathrm{~d}$ apart; the rats lever pressed for $10 \%$ sucrose during the intervening daily sessions.

Experiment 2: Nicotine self-administration, extinction, and reinstatement. The nicotine self-administration procedure was based on previous reports (Corrigall and Coen, 1989; Buczek et al., 1999). Initially, the rats were trained to self-administer nicotine $(0.03 \mathrm{mg} / \mathrm{kg}$ per infusion $)$ for 1 $\mathrm{h} / \mathrm{d}$ for $24 \mathrm{~d}$. At the start of the sessions, the red house light was turned on, the retractable lever was extended, and the white cue light above the retractable lever was illuminated for $30 \mathrm{~s}$. Each nicotine infusion was accompanied by a $40 \mathrm{~s}$ time-out, during which responses were recorded but did not lead to drug delivery; during the time-out period, the cue light was illuminated. During days $1-10$, active lever responding was reinforced under an FR-1 schedule; during days 11-16 and 17-24, responding was reinforced under FR-2 and FR-5 schedules, respectively. After the 24th session, a nicotine dose-response curve was determined during sessions 25-33 under an FR-5 schedule. The order in which the doses were presented was $0.060,0.030$, and $0.015 \mathrm{mg} / \mathrm{kg}$ per infusion, and the rats were given three sessions at each dose. The data from 9 of the 30 rats were excluded because of loss of catheter patency during training. The conditions during the $1 \mathrm{~h}$ extinction sessions were the same as during the training phase, except that lever responding under the FR-5 schedule led to the delivery of saline infusions. The saline infusions were accompanied by the illumination of the cue light that was previously paired with nicotine infusions for $40 \mathrm{~s}$. The rats were given 7-23 extinction sessions until they reached an extinction criterion of fewer than 15 presses on the active lever per $1 \mathrm{~h}$. During the extinction phase, the rats were injected at least three times with subcutaneous saline $30 \mathrm{~min}$ before the sessions to habituate them to the injection procedure. The extinction session during which the rats reached the extinction criterion after the subcutaneous saline injection served as a baseline against which the effect of nicotine priming injections on reinstatement was compared. On the next day, the effect of a priming injection of nicotine $(0.15 \mathrm{mg} / \mathrm{kg}$, s.c.; $30 \mathrm{~min}$ pretreatment time) on the reinstatement of nicotine seeking was examined. We chose the subcutaneous route because we and others have found that the priming effect of subcutaneous nicotine is more robust (and reproducible) than that of intravenous nicotine (Shaham et al., 1997; Andreoli et al., 2003; LeSage et al., 2004).

Experiment 3: Cocaine self-administration, extinction, and reinstatement. Cocaine self-administration was conducted in a manner similar to that described in Experiment 2 for nicotine. The rats $(n=11$ per line) were trained to self-administer cocaine $(0.75 \mathrm{mg} / \mathrm{kg}$ per infusion) for 1 $\mathrm{h} / \mathrm{d}$. During days $1-7$, active lever responding was reinforced under an FR-1 schedule; during days 8-9 and 10-14, responding was reinforced under FR-2 and FR-5 schedules, respectively. Subsequently, a cocaine dose-response curve was determined under an FR-5 schedule. The dif- 
ferent doses were given in the following order: $0.375,0.75,1.125,0.75$, and $0.1875 \mathrm{mg} / \mathrm{kg}$ per infusion, each for $2 \mathrm{~d}$. The data from 2 of the 22 rats were excluded because of loss of catheter patency during training.

The extinction of lever responding for cocaine was performed in a manner similar to that described in Experiment 2 for nicotine, but for a longer time period. The rats were given 14-31 extinction sessions until they reached an extinction criterion of fewer than 15 presses on the active lever per $1 \mathrm{~h}$. During the extinction phase, the rats were injected at least 3 times with saline (intraperitoneally) $15 \mathrm{~min}$ before the sessions to habituate them to the injection procedure. The extinction session during which the rats reached the extinction criterion after the intraperitoneal saline injection served as a baseline against which the effect of cocaine priming injections on reinstatement was compared. One P rat did not reach the extinction criterion after 31 extinction sessions and was excluded. The effect of priming injections of cocaine $(5.0$ and $10.0 \mathrm{mg} / \mathrm{kg}$, i.p.; 15 min pretreatment time) on reinstatement of cocaine seeking was examined in the $\mathrm{P}$ and $\mathrm{NP}$ rats in a counterbalanced manner. Two to four extinction sessions were conducted between the tests of each priming dose until the extinction criterion was again achieved. Finally, at the end of the experiment, the rats were injected in a counterbalanced order with either saline or nicotine $(0.15 \mathrm{mg} / \mathrm{kg}$, s.c.) during two daily sessions, and the effect of these injections on reinstatement of cocaine seeking was determined.

Statistical analyses. The data from the different phases of the experiments were analyzed with ANOVAs using the appropriate between- and within-subjects factors (see Results). Significant effects $(p<0.05)$ were followed by post hoc (Newman-Keuls) tests. Because the number of responses on the inactive lever was fewer than three per hour in the different phases of the experiments presented below, these data are not shown.

\section{Results}

\section{Experiment 1: Sucrose}

Experiment 1a

The rats in both groups rapidly learned the operant task within one to two sessions. During the first three sessions, sucrose intake was lower in the P rats than in the NP rats (P rats: $10.5 \pm 1.3 \mathrm{ml}$ per $2 \mathrm{~h} / \mathrm{d}$; NP rats: $13.4 \pm 0.8 \mathrm{ml}$ per $2 \mathrm{~h} / \mathrm{d} ; n=15$ per line; $F_{(2,56)}=4.9 ; p<0.05$; for effect of rat line by training day). Over the last six sessions, however, the $\mathrm{P}$ rats increased their sucrose intake, whereas the sucrose intake in the NP rats remained stable, resulting in higher intake in the $P$ rats $(P$ rats: $19.9 \pm 1.0 \mathrm{ml}$ per 1 $\mathrm{h} / \mathrm{d} ; \mathrm{NP}$ rats: $12.9 \pm 0.7 \mathrm{ml}$ per $1 \mathrm{~h} / \mathrm{d} ; F_{(1,28)}=34.5$ and $F_{(5,140)}=$ $2.9 ; p<0.05$; for effects of rat line and rat line by training day).

\section{Experiment $1 b$}

As in Experiment 1a, the lever responding for sucrose of the P rats was initially lower than that of the NP rats. Over time, however, the $P$ rats increased their lever responding to a greater degree than the NP rats, resulting in higher intake in the $\mathrm{P}$ rats during sessions 6-10 (Fig. 1a). The statistical analysis for the number of sucrose rewards earned revealed significant effects of rat line $\left(F_{(1,19)}=\right.$ $8.7 ; p<0.01)$ and rat line by training day $\left(F_{(9,171)}=10.9 ; p<\right.$ $0.01)$. The $\mathrm{P}$ rats also self-administered more sucrose during the subsequent concentration-response determination (Fig. 1b). The statistical analysis of the number of sucrose rewards earned revealed significant main effect of rat line $\left(F_{(1,19)}=42.2 ; p<\right.$ $0.01)$ and significant interaction effect of rat line by sucrose concentration $\left(F_{(3,57)}=5.28 ; p<0.01\right)$.

\section{Experiment 2: Nicotine}

\section{Self-administration}

Figure 2, $a$ and $b$, presents the mean \pm SEM number of infusions and active lever responses during the first 24 sessions of training under FR-1, FR-2, and FR-5 reinforcement schedules (nicotine dose of $0.03 \mathrm{mg} / \mathrm{kg}$ per infusion). Nicotine intake during this time period was substantially higher in the P rats than in the NP rats
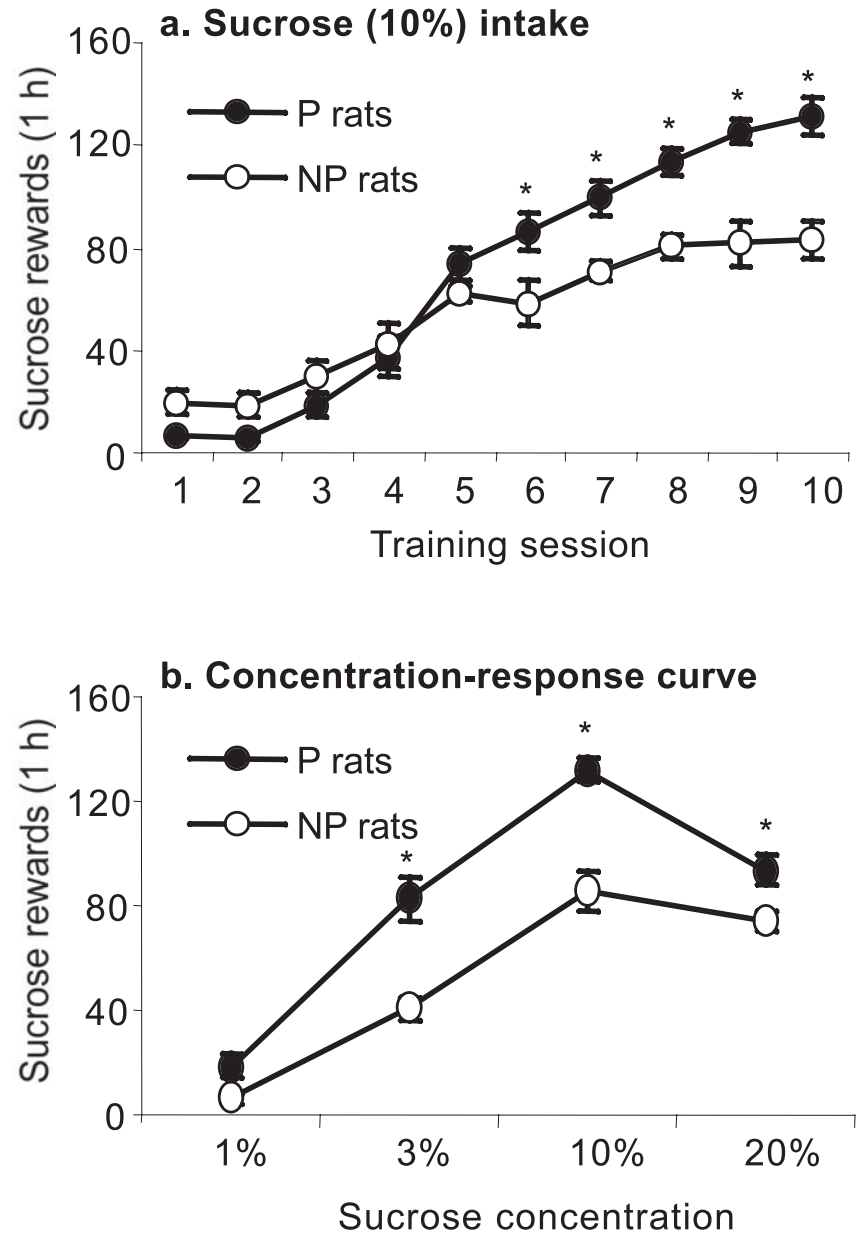

Figure 1. Sucrose self-administration in $P$ and NP rats. $\boldsymbol{a}$, Mean \pm SEM number of sucrose deliveries during the first $10 \mathrm{~d}$ of sucrose $(10 \%)$ self-administration $(0.19 \mathrm{ml}$ per reward delivery) under an FR-1 reinforcement schedule (each lever press was reinforced). $\boldsymbol{b}$, Mean \pm SEM number of sucrose deliveries as a function of the sucrose concentration; data are from the concentration-response determination during days $11-22$ of sucrose self-administration ( $3 \mathrm{~d}$ per dose). ${ }^{*}$ Different from the NP group; $p<0.05$ (Newman-Keuls post hoc test); $n=11$ per line.

(Fig. 2a). Both the P and the NP rats, however, maintained their daily nicotine intake when the schedule requirement was increased to FR- 2 and FR- 5 by increasing their active lever responding (Fig. 2b). For the number of infusions under the FR-1 schedule, significant effects were found for rat line and rat line by training day $\left(F_{(1,19)}=19.9\right.$ and $\left.F_{(9,171)}=6.8 ; p<0.01\right)$. Under the FR-2 schedule, significant effects were found for rat line and rat line by training day $\left(F_{(1,19)}=35.9\right.$ and $\left.F_{(4,76)}=4.3 ; p<0.01\right)$, whereas for the FR-5 schedule, there was a significant effect of rat line $\left(F_{(1,19)}=48.1 ; p<0.01\right)$.

Figure 2, $c$ and $d$, presents the mean \pm SEM number of infusions and daily intake (milligrams per kilogram) during the doseresponse determination (sessions 25-33). Independent of the nicotine dose, the P rats self-administered more nicotine than the NP rats. Overall, for both the $\mathrm{P}$ and NP rats, increasing the dose of nicotine led to large increases in their daily intake. For the P rats, increasing the nicotine dose led to decreases in the number of infusions, whereas for the NP rats, the dose-response curve remained relatively flat. The statistical analysis for the number of infusions revealed significant effects of rat line and rat line by nicotine dose $\left(F_{(1,62)}=99.8\right.$ and $\left.F_{(1,62)}=7.2 ; p<0.01\right)$. The statistical analysis for nicotine intake (milligrams per kilogram) 

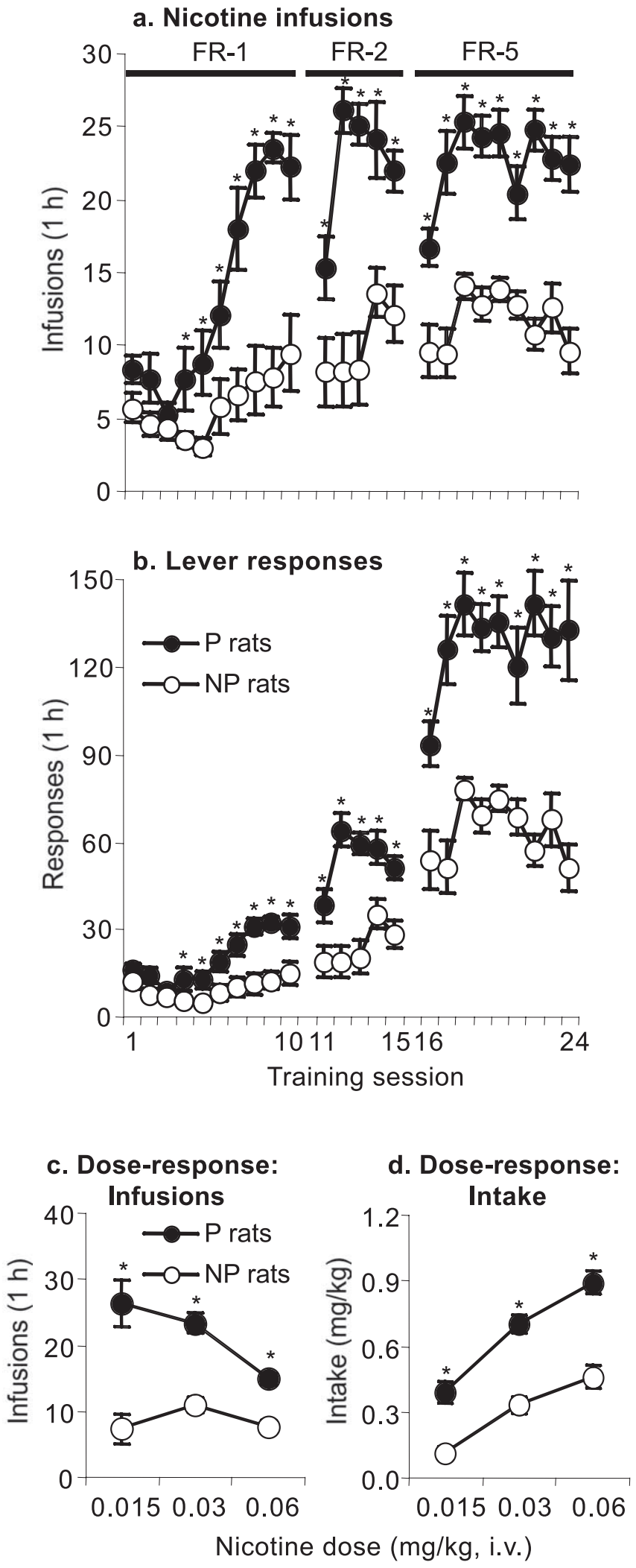

Figure 2. Nicotine self-administration in P and NP rats. $\boldsymbol{a}, \boldsymbol{b}$, Mean \pm SEM number of nicotine infusions and active lever responses during the first $24 \mathrm{~d}$ of nicotine self-administration $(0.03 \mathrm{mg} / \mathrm{kg}$ per infusion) under FR-1, FR-2, and FR-5 reinforcement schedules. $\boldsymbol{c}, \boldsymbol{d}$, Mean \pm SEM number of nicotine infusions and nicotine intake (milligrams per kilogram); data are from the dose-response determination during days $25-33$ of nicotine self-administration training ( $3 \mathrm{~d}$ per dose). *Different from the NP group; $p<0.05$ (Newman-Keuls post hoc test); $n=$ 9-12 per line.
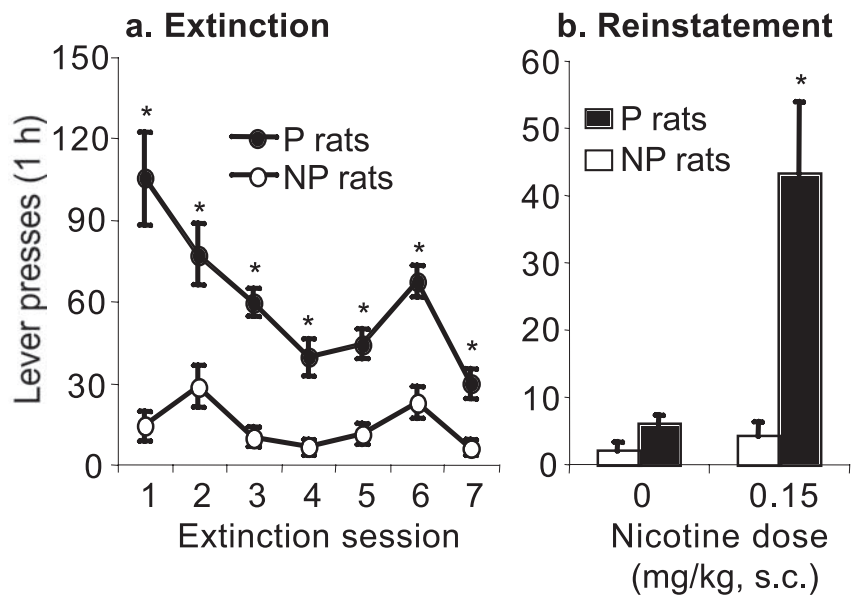

Figure 3. Extinction and reinstatement of nicotine seeking in P and NP rats. $\boldsymbol{a}$, Mean \pm SEM number of responses on the previously active lever during the first seven sessions of the extinction phase. During this phase, lever responding led to saline infusions and the illumination of the cue light previously paired with nicotine infusions. $\boldsymbol{b}$, Mean \pm SEM number of responses on the previously active lever during the tests for reinstatement of nicotine seeking induced by priming injections of saline or nicotine $(0.15 \mathrm{mg} / \mathrm{kg}$, s.c). During the reinstatement tests, lever responding was not reinforced with nicotine. *Different from the NP group; $p<0.05 ; n=$ 9-12 per line.

revealed significant main effects of nicotine dose $\left(F_{(2,62)}=4.3\right.$; $p<0.05)$ and rat line $\left(F_{(1,62)}=30.6 ; p<0.01\right)$.

\section{Extinction}

Figure $3 a$ presents the mean \pm SEM number of active lever responses during the first seven extinction sessions, during which all rats were exposed to the extinction conditions. Lever responding in the presence of the nicotine-associated cues in the extinction sessions was substantially higher in the P rats than in the NP rats. The statistical analysis of the first seven extinction sessions revealed significant effects of rat line and rat line by extinction day $\left(F_{(1,19)}=34.8\right.$ and $\left.F_{(6,114)}=5.9 ; p<0.01\right)$. The P rats were also more resistant to extinction, as indicated by the higher number of extinction sessions that they needed to reach the extinction criterion of 15 presses on the active lever per hour (P rats: $8.9 \pm$ $2.0 ; \mathrm{NP}$ rats: $2.00 \pm 0.8 ; F_{(1,19)}=28.3 ; p<0.01$ for the effect of rat line).

\section{Reinstatement}

Figure $3 b$ presents the mean \pm SEM number of active lever responses during the tests for reinstatement after noncontingent priming injections of saline or nicotine; these tests were conducted after 7-23 extinction sessions when rats met the extinction criterion of fewer than 15 responses on the active lever. Nicotine priming injections reinstated lever responding in the $\mathrm{P}$ rats but not in the NP rats. The statistical analysis revealed significant effects of rat line and rat line by nicotine dose $\left(F_{(1,39)}=14.8\right.$ and $\left.F_{(1,39)}=9.7 ; p<0.01\right)$.

\section{Experiment 3: Cocaine}

Self-administration

Figure $4, a$ and $b$, shows the mean \pm SEM number of cocaine infusions and active lever presses during the first 16 sessions of training under the FR-1, FR-2, and FR-5 reinforcement schedules (cocaine dose of $0.75 \mathrm{mg} / \mathrm{kg}$ per infusion). There were no significant P-NP differences for cocaine self-administration under these reinforcement schedules. During the initial seven sessions under the FR-1 schedule, both the P and NP rats increased their cocaine intake over time $\left(F_{(6,114)}=6.9 ; p<0.01\right.$ for the effect of 

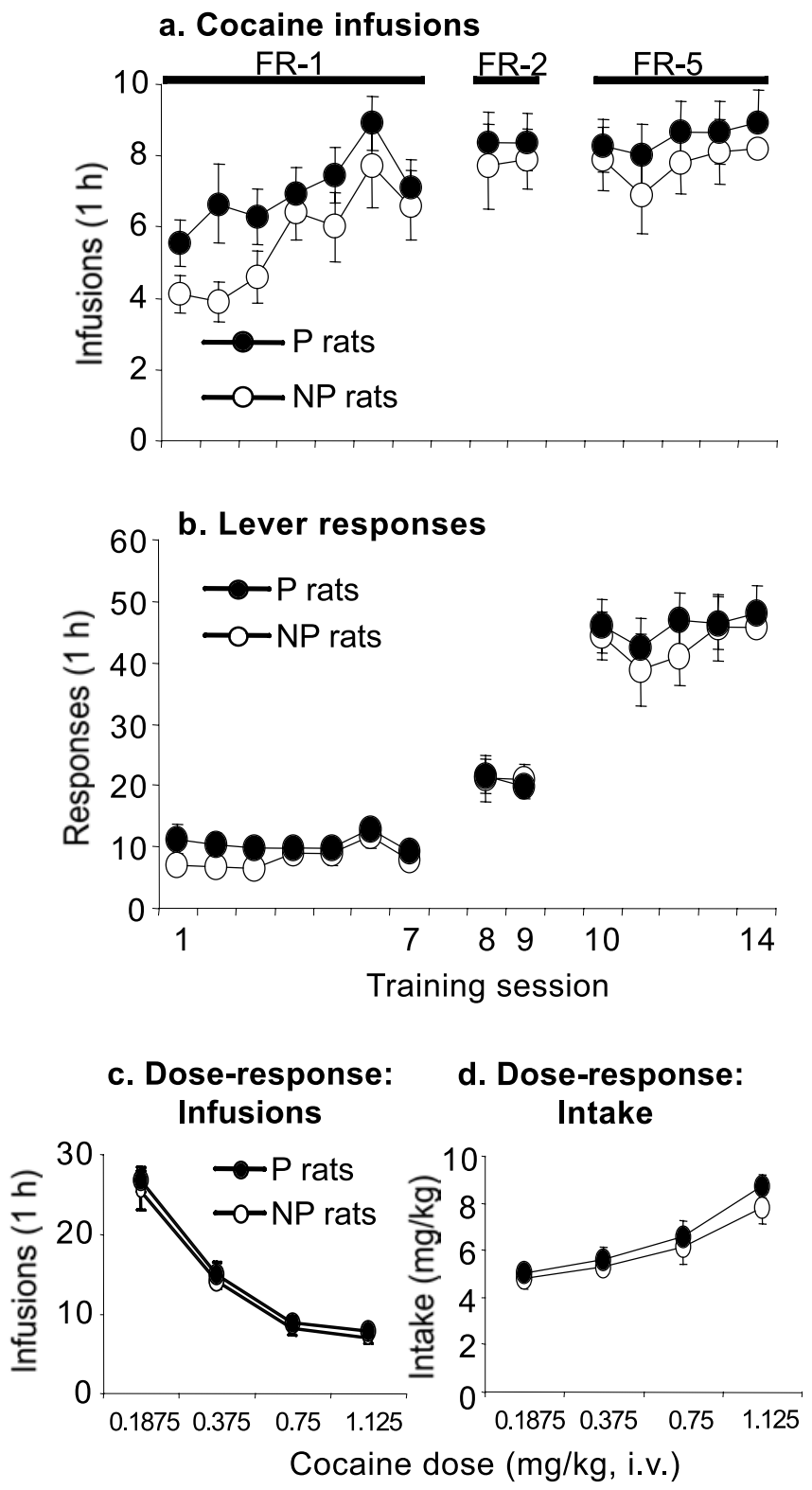

Figure 4. Cocaine self-administration in P and NP rats. $\boldsymbol{a}, \boldsymbol{b}$, Mean \pm SEM number of cocaine infusions and active lever responses during the first $14 \mathrm{~d}$ of cocaine self-administration $(0.75$ $\mathrm{mg} / \mathrm{kg}$ per infusion) under FR-1, FR-2, and FR-5 reinforcement schedules. $\boldsymbol{c}, \boldsymbol{d}$, Mean \pm SEM number of cocaine infusions and cocaine intake (milligrams per kilogram); data are from the dose-response determination during days $15-22$ of cocaine self-administration ( $2 \mathrm{~d}$ per dose; $n=9-11$ per line).

training day). The $\mathrm{P}$ and NP rats maintained their daily cocaine intake when the schedule requirement was increased from FR-1 to FR-2 and then to FR-5 by increasing their lever responding (Fig. $4 a, b$ ). There were no P-NP differences for the number of cocaine infusions or active lever presses under the FR-1, FR-2, and FR-5 reinforcement schedules $(p>0.1)$. Figure $4, c$ and $d$, presents the mean \pm SEM number of cocaine infusions and daily intake (milligrams per kilogram) during the subsequent doseresponse determination (two sessions per dose); there were no $\mathrm{P}-\mathrm{NP}$ differences. Both the $\mathrm{P}$ and NP rats demonstrated the characteristic responding on the descending limb of the cocaine doseresponse curve (Yokel, 1987): decreases in the number of infusions per session for increasing cocaine doses (Fig. 4c) and overall increases in total cocaine intake (Fig. $4 d$ ). The statistical analysis for the number of cocaine infusions and total intake revealed a significant effect of cocaine dose $\left(F_{(3,55)}=194.0\right.$ and $F_{(3,55)}=$ $50.1 ; p<0.01$, respectively). The effects of rat line and rat line by cocaine dose were not significant $(p>0.1)$.

\section{Extinction}

Figure $5 a$ presents the mean \pm SEM number of active lever responses during the first 14 extinction sessions, during which all rats were exposed to the extinction conditions. Lever responding in the presence of the cocaine-associated cues during the extinction sessions was higher in the $\mathrm{P}$ rats than in the NP rats. The statistical analysis of the first 14 extinction sessions revealed significant effects of rat line by day $\left(F_{(13,234)}=1.76 ; p=0.05\right)$ and extinction day $\left(F_{(13,234)}=18.0 ; p<0.01\right)$. During the first $14 \mathrm{~d}$ of extinction, active lever responding was consistently higher in the $\mathrm{P}$ rats, which lever pressed $\sim 70 \%$ more than the NP rats on the first extinction day $\left(F_{(1,18)}=5.1 ; p<0.05\right)$. Additional evidence supporting the increased resistance to extinction in the $\mathrm{P}$ rats is the significantly higher number of extinction sessions that it took for the $\mathrm{P}$ rats to reach the extinction criterion of 15 presses on the active lever per hour ( $\mathrm{P}$ rats: $12.4 \pm 1.6$; NP rats: $6.7 \pm 1.4$; $F_{(1,18)}=7.1 ; p<0.05$ for rat line).

\section{Reinstatement}

Figure $5 b$ presents the mean \pm SEM number of active lever responses during the tests for reinstatement after noncontingent priming injections of saline or cocaine; these tests were conducted after 14-31 extinction sessions when rats met the extinction criterion of fewer than 15 responses on the active lever. Injections of the low dose of cocaine priming ( $5 \mathrm{mg} / \mathrm{kg}$ ) reinstated lever responding in the $\mathrm{P}$ rats to a greater degree than in the NP rats; no P-NP differences were observed with the higher cocaine dose $(10 \mathrm{mg} / \mathrm{kg})$. The statistical analysis revealed effects of cocaine dose $\left(F_{(2,18)}=26.9 ; p<0.01\right)$, rat line $\left(F_{(1,18)}=4.3 ; p<\right.$ $0.05)$, and rat line by cocaine dose interaction that approached significance $\left(F_{(2,18)}=2.8 ; p=0.07\right)$. In addition, in subsequent tests, nicotine priming injections reinstated cocaine seeking in the $\mathrm{P}$ rats but not the NP rats (Fig. $5 c$ ). The statistical analysis revealed significant effects of nicotine dose $\left(F_{(1,16)}=19.8 ; p<\right.$ $0.01)$, rat line $\left(F_{(1,16)}=70.2 ; p<0.01\right)$, and rat line by nicotine dose $\left(F_{(1,16)}=32.3 ; p<0.01\right)$.

\section{Discussion}

We assessed three measures of nicotine-taking behavior in alcohol-naive offspring of $\mathrm{P}$ and NP rats that were selectively bred for high and low alcohol intake (Li et al., 1993). First, we used a drug self-administration procedure that has been used to assess the reinforcing effects of nicotine and other drugs (Picciotto and Corrigall, 2002; Wise, 2004). Second, we used an extinction procedure that has been used to assess the conditional motivational effects of cues previously paired with nicotine and other drug and nondrug reinforcers (Balleine and Dickinson, 1998; Everitt et al., 1999; Caggiula et al., 2001; Shalev et al., 2002; Lu et al., 2004a). Third, we used a reinstatement procedure that has been used to assess relapse to alcohol and drug seeking induced by acute reexposure to the self-administered drug or other stimuli (Stewart, 2000; Le and Shaham, 2002; Shaham et al., 2003; Weiss, 2005). We found that nicotine-taking behavior in these tests was significantly higher in $\mathrm{P}$ rats than in NP rats. These data, which were obtained from preclinical self-administration and relapse models, support the hypothesis that nicotine and alcohol addiction share a common genetic vulnerability. 


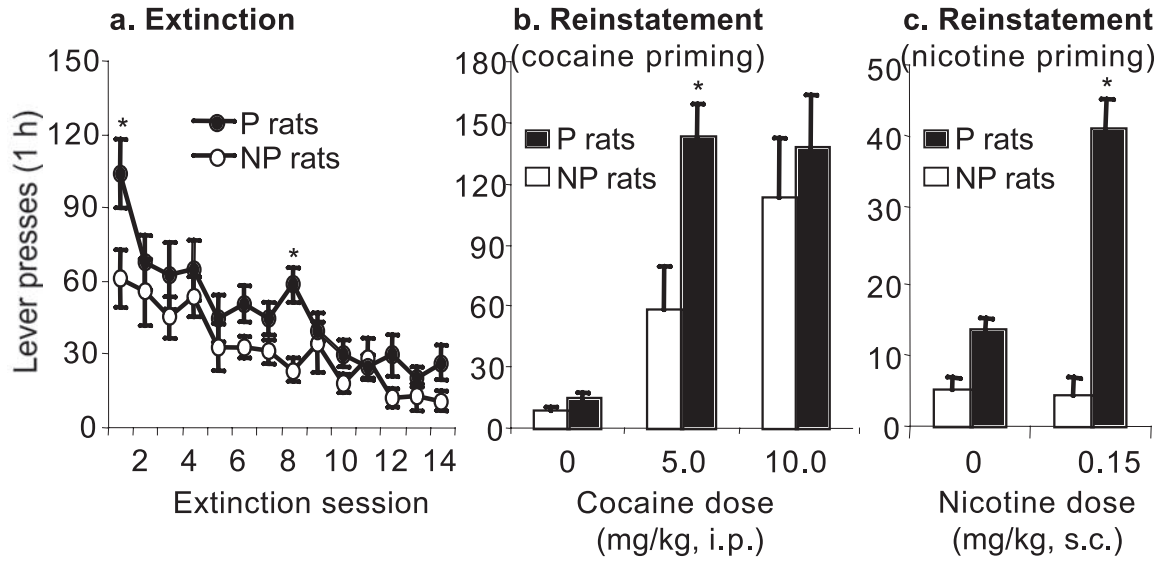

Figure 5. Extinction and reinstatement of cocaine seeking in P and NP rats. $\boldsymbol{a}$, Mean \pm SEM number of responses on the previously active lever during the first 14 sessions of the extinction phase. During this phase, lever responding led to saline infusions and the illumination of the cue light previously paired with cocaine infusions. $\boldsymbol{b}$, Mean \pm SEM number of responses on the previously active lever during the tests for reinstatement of cocaine seeking induced by priming injections of saline and cocaine ( 5 and $10 \mathrm{mg} / \mathrm{kg}$, i.p.). c, Mean \pm SEM number of responses on the previously active lever during the tests for reinstatement of cocaine seeking induced by priming injections of saline and nicotine $(0.15 \mathrm{mg} / \mathrm{kg}$, s.c.). During the reinstatement tests, lever responding was not reinforced with cocaine. ${ }^{*}$ Different from the NP group; $p<0.05 ; n=9-11$ per line.

\section{Nicotine-taking behavior in $\mathrm{P}$ and NP rats}

Over a range of nicotine doses and response costs, $\mathrm{P}$ rats selfadministered more nicotine than NP rats. This effect is not the result of learning deficits. NP rats rapidly learned to selfadminister oral sucrose and, over the first $3 \mathrm{~d}$ of training, acquired the operant task more rapidly than $\mathrm{P}$ rats (Fig. 1). The $\mathrm{P}-\mathrm{NP}$ differences are also not the result of the failure of NP rats to acquire nicotine self-administration. NP rats increased their lever responding and consequently maintained a relatively stable daily nicotine intake when the schedule requirement was changed from FR-1 to FR-2 and FR-5 (Fig. 2a). Furthermore, the pattern of nicotine self-administration and the daily intake in NP rats $(\sim 12$ infusions per hour for a dose of $0.03 \mathrm{mg} / \mathrm{kg}$ under an FR-5 schedule) was similar to those reported for Long-Evans and Wistar rats (Corrigall and Coen, 1989; Chiamulera et al., 1996; Shaham et al., 1997).

We interpret the upward shift in the nicotine dose-response curve (Fig. $2 c, d$ ) in $\mathrm{P}$ rats to suggest that nicotine has greater reinforcing effects in $\mathrm{P}$ rats than in NP rats. This interpretation is based on the conceptualization of Piazza and colleagues (2000) who argued, on the basis of several lines of evidence, that upward shifts in the dose-response curve in drug self-administration studies reflect increases in the reinforcing effects of the drug. An alternative interpretation is that the higher number of infusions on the descending limb of the nicotine dose-response curve (a shift to the right of the curve) in $\mathrm{P}$ rats (Fig. $2 c$ ) is caused by decreases in the reinforcing effects of nicotine in these rats. This interpretation, however, is unlikely. The findings of higher lever responding in $\mathrm{P}$ rats during the extinction and reinstatement tests (Fig. $3 a, b$ ) are not compatible with the notion that nicotine is a weaker reinforcer in P rats than in NP rats. Furthermore, under our training conditions, manipulations that decrease the reinforcing effects of nicotine, such as injections of nicotine receptor antagonists or lesions of the mesolimbic dopamine system, decrease rather than increase nicotine self-administration (Rose and Corrigall, 1997; Picciotto and Corrigall, 2002).

Nicotine injections enhance the conditioned reinforcing effects of stimuli paired with natural reinforcers (Olausson et al., 2004), and recent studies have demonstrated a critical role of environmental cues in nicotine self-administration (Caggiula et al., 2001; Donny et al., 2003). These investigators found that lever presses that lead to the delivery of a brief visual stimulus, a weak reinforcer in rats (DerocheGamonet et al., 2002; Donny et al., 2003), are increased to similar degrees by contingent or noncontingent nicotine infusions. On the basis of these findings, Caggiula and colleagues (2001) suggested that nicotine-taking behavior is primarily the result of the ability of nicotine to potentiate the reinforcing effects of other stimuli in the drug environment. In our study, as in many other nicotine selfadministration studies, lever presses were accompanied by a light cue. Thus, on the basis of the hypothesis of Caggiula et al. (2001), increases in nicotine-taking behavior in $\mathrm{P}$ rats may be caused by increased sensitivity to the effects of nicotine on behaviors maintained by nondrug stimuli in the drug environment, rather than differences in the reinforcing effects of acute unconditioned nicotine. To the degree that drug priming injections reinstate drug seeking by restoring the incentive value of extinguished drug cues (Stewart et al., 1984), the finding that noncontingent nicotine priming injections reinstate lever responding in $\mathrm{P}$ rats but not NP rats (Fig. $3 b$ ) is compatible with this speculation.

Finally, P-NP differences in extinction responding in the presence of nicotine (or cocaine) cues may reflect genetic differences in sensitivity to drug-associated cues; however, for the nicotine-trained rats, drug intake during the self-administration phase was higher in $\mathrm{P}$ rats than in NP rats. Thus, $\mathrm{P}-\mathrm{NP}$ differences in extinction responding may be caused by additional nicotinecue pairing in $\mathrm{P}$ rats, which subsequently resulted in increased responsiveness to nicotine cues in these rats. The data from Experiment 3, however, tentatively support the notion that genetics may play a role in $\mathrm{P}-\mathrm{NP}$ differences in responsiveness to drug cues. We found $\mathrm{P}-\mathrm{NP}$ differences in the response to cocaine cues in the extinction tests, despite the fact that the number of cocaine-cue pairings during self-administration was similar in the two rat lines.

\section{Sucrose- and cocaine-taking behavior in $\mathrm{P}$ and NP rats}

We determined the generality of our findings with nicotine by assessing $\mathrm{P}-\mathrm{NP}$ differences in sucrose self-administration, cocaine self-administration, cocaine seeking induced by cocaine cues in extinction tests, and cocaine (and nicotine) priminginduced reinstatement tests. Over a range of sucrose concentrations, $\mathrm{P}$ rats self-administered more sucrose than NP rats. This finding is consistent with previous studies in which it was found that the P rats consume greater amounts of sucrose (Stewart et al., 1994; Eiler et al., 2005). Our data for sucrose self-administration are also consistent with results from human studies on the association between alcoholism and sucrose palatability and preference (Kampov-Polevoy et al., 1997, 1999, 2003).

A major finding here is that over a range of doses, cocaine self-administration was remarkably similar in $\mathrm{P}$ and NP rats. In contrast, $\mathrm{P}-\mathrm{NP}$ differences in cocaine seeking emerged in subsequent extinction and cocaine priming-induced reinstatement tests; in both cases, lever responding was somewhat higher in $\mathrm{P}$ rats than in NP rats. Marked P-NP differences also were found 
during a final test for nicotine priming-induced reinstatement of cocaine seeking (Fig. $5 c$ ). The lack of $\mathrm{P}-\mathrm{NP}$ differences in cocaine self-administration under fixed ratio schedules, a procedure commonly used to measure the acute reinforcing effects of cocaine (Wise, 1978; Roberts et al., 1980), appears to be inconsistent with results from correlational human data on comorbidity of cocaine and alcohol dependence (Bierut et al., 1998; Merikangas et al., 1998; Nurnberger et al., 2004). Unlike alcohol and nicotine, however, for which it was established that genetic factors contribute significantly to comorbidity between these drugs (True et al., 1999), genetic contributions to alcohol and cocaine comorbidity have not yet been clearly established (Goldman and Bergen, 1998; Goldman et al., 2005). In interpreting the potential discrepancy between human cocaine-alcohol comorbidity and the present data on the lack of P-NP differences in cocaine selfadministration, it is also important to note that differences in the magnitude of the acute reinforcing effects of the drug, as measured in self-administration models, do not readily predict compulsive drug use and relapse in humans (Volkow and Fowler, 2000; Kalivas and Volkow, 2005) and laboratory rats (Shalev et al., 2002; Deroche-Gamonet et al., 2004; Vanderschuren and Everitt, 2004). In this regard, to the degree that extinction and reinstatement procedures model human drug relapse, the findings of P-NP differences in extinction responding and cocaineand nicotine-induced reinstatement of cocaine seeking (Figs. 3, 5 ) are consistent with the notion of a general genetic factor in human addictions (Uhl et al., 2002), because relapse vulnerability is a core feature of addiction (O'Brien, 2005).

Finally, the findings on the lack of P-NP differences in cocaine self-administration are consistent with those of Eiler et al. (2005), who reported lack of $\mathrm{P}-\mathrm{NP}$ differences for medial forebrain bundle stimulation threshold, an established measure of reward sensitivity (Wise, 1996). The findings of the lack of P-NP differences in cocaine self-administration and brain stimulation reward indicate that $\mathrm{P}-\mathrm{NP}$ differences in nicotine-taking behavior are not the result of general reward deficits in NP rats.

\section{Concluding remarks}

The prevalence of smoking in human alcoholics is much higher than in the general population, and results from twin studies have led to the hypothesis that a shared genetic vulnerability underlies alcohol and nicotine addiction. Here, we provided experimental evidence from rat models of drug self-administration and relapse that supports this hypothesis. Alcohol-naive offspring of rats that were selectively bred for high and low alcohol intake demonstrated differences in nicotine-taking behavior that were as profound as those found previously with $\mathrm{P}$ and NP rats for alcoholtaking behavior. These findings suggest that these lines of rats can be as useful for the study of determinants of nicotine addiction as they have been for the study of alcohol addiction in animal models.

\section{References}

Andreoli M, Tessari M, Pilla M, Valerio E, Hagan JJ, Heidbreder CA (2003) Selective antagonism at dopamine D3 receptors prevents nicotinetriggered relapse to nicotine-seeking behavior. Neuropsychopharmacology 28:1272-1280.

Balleine BW, Dickinson A (1998) Goal-directed instrumental action: contingency and incentive learning and their cortical substrates. Neuropharmacology 37:407-419.

Bierut LJ, Dinwiddie SH, Begleiter H, Crowe RR, Hesselbrock V, Nurnberger Jr JI, Porjesz B, Schuckit MA, Reich T (1998) Familial transmission of substance dependence: alcohol, marijuana, cocaine, and habitual smoking: a report from the Collaborative Study on the Genetics of Alcoholism. Arch Gen Psychiatry 55:982-988.
Bierut LJ, Rice JP, Goate A, Hinrichs AL, Saccone NL, Foroud T, Edenberg HJ, Cloninger CR, Begleiter H, Conneally PM, Crowe RR, Hesselbrock V, Li TK, Nurnberger Jr JI, Porjesz B, Schuckit MA, Reich T (2004) A genomic scan for habitual smoking in families of alcoholics: common and specific genetic factors in substance dependence. Am J Med Genet A 124:19-27.

Buczek Y, Lê AD, Wang A, Stewart J, Shaham Y (1999) Stress reinstates nicotine seeking but not sucrose solution seeking in rats. Psychopharmacology 144:183-188.

Caggiula AR, Donny EC, White AR, Chaudhri N, Booth S, Gharib MA, Hoffman A, Perkins KA, Sved AF (2001) Cue dependency of nicotine selfadministration and smoking. Pharmacol Biochem Behav 70:515-530.

Carmelli D, Swan GE, Robinette D, Fabsitz R (1992) Genetic influence on smoking: a study of male twins. N Engl J Med 327:829-833.

Chiamulera C, Borgo C, Falchetto S, Valerio E, Tessari M (1996) Nicotine reinstatement of nicotine self-administration after long-term extinction. Psychopharmacology 127:102-107.

Corrigall WA, Coen KM (1989) Nicotine maintains robust selfadministration in rats on a limited access schedule. Psychopharmacology 99:473-478.

De Fiebre CM, Medhurst LJ, Collins AC (1987) Nicotine response and nicotinic receptors in long-sleep and short-sleep mice. Alcohol 4:493-501.

Deroche-Gamonet V, Piat F, Le Moal M, Piazza PV (2002) Influence of cue-conditioning on acquisition, maintenance and relapse of cocaine intravenous self-administration. Eur J Neurosci 15:1363-1370.

Deroche-Gamonet V, Belin D, Piazza PV (2004) Evidence for addiction-like behavior in the rat. Science 305:1014-1017.

Donny EC, Chaudhri N, Caggiula AR, Evans-Martin FF, Booth S, Gharib MA, Clements LA, Sved AF (2003) Operant responding for a visual reinforcer in rats is enhanced by noncontingent nicotine: implications for nicotine self-administration and reinforcement. Psychopharmacology 169:68-76

Eiler II WJ, Woods II JE, Masters J, McKay PF, Hardy III L, Goergen JJ, Mensah-Zoe B, Cook JB, Johnson NJ, June HL (2005) Brain stimulation reward performance and sucrose maintained behaviors in alcoholpreferring and -nonpreferring rats. Alcohol Clin Exp Res 29:571-583.

Enoch MA, Goldman D (2001) The genetics of alcoholism and alcohol abuse. Curr Psychiatry Rep 3:144-151.

Everitt BJ, Parkinson JA, Olmstead MC, Arroyo M, Robledo P, Robbins TW (1999) Associative processes in addiction and reward: the role of amygdala-ventral striatal subsystems. Ann NY Acad Sci 877:412-438.

Goldman D, Bergen A (1998) General and specific inheritance of substance abuse and alcoholism. Arch Gen Psychiatry 55:964-965.

Goldman D, Oroszi G, Ducci F (2005) The genetics of addictions: uncovering the genes. Nat Rev Genet 6:521-532.

Gordon TL, Meehan SM, Schechter MD (1993) P and NP rats respond differently to the discriminative stimulus effects of nicotine. Pharmacol Biochem Behav 45:305-308.

Istvan J, Matarazzo JD (1984) Tobacco, alcohol, and caffeine use: a review of their interrelationships. Psychol Bull 95:301-326.

Kalivas PW, Volkow ND (2005) The neural basis of addiction: a pathology of motivation and choice. Am J Psychiatry 162:1403-1413.

Kampov-Polevoy A, Garbutt JC, Janowsky D (1997) Evidence of preference for a high-concentration sucrose solution in alcoholic men. Am J Psychiatry 154:269-270.

Kampov-Polevoy AB, Garbutt JC, Janowsky DS (1999) Association between preference for sweets and excessive alcohol intake: a review of animal and human studies. Alcohol Alcohol 34:386-395.

Kampov-Polevoy AB, Garbutt JC, Khalitov E (2003) Family history of alcoholism and response to sweets. Alcohol Clin Exp Res 27:1743-1749.

Kandel D, Chen K, Warner LA, Kessler RC, Grant B (1997) Prevalence and demographic correlates of symptoms of last year dependence on alcohol, nicotine, marijuana and cocaine in the U.S. population. Drug Alcohol Depend 44:11-29.

Krishnan KR (2005) Psychiatric and medical comorbidities of bipolar disorder. Psychosom Med 67:1-8.

Lê A, Shaham Y (2002) Neurobiology of relapse to alcohol in rats. Pharmacol Ther 94:137-156.

Lê AD, Corrigall WA, Harding JW, Juzytsch W, Li TK (2000) Involvement of nicotinic receptors in alcohol self-administration. Alcohol Clin Exp Res 24:155-163.

Lê AD, Wang A, Harding S, Juzytsch W, Shaham Y (2003) Nicotine in- 
creases alcohol self-administration and reinstates alcohol seeking in rats. Psychopharmacology 168:216-221.

LeSage MG, Burroughs D, Dufek M, Keyler DE, Pentel PR (2004) Reinstatement of nicotine self-administration in rats by presentation of nicotinepaired stimuli, but not nicotine priming. Pharmacol Biochem Behav 79:507-513

Li TK, Lumeng L, Doolittle DP (1993) Selective breeding for alcohol preference and associated responses. Behav Genet 23:163-170.

Lu L, Grimm JW, Hope BT, Shaham Y (2004a) Incubation of cocaine craving after withdrawal: a review of preclinical data. Neuropharmacology 47 [Suppl 1]:214-226.

Lu L, Grimm JW, Dempsey J, Shaham Y (2004b) Cocaine seeking over extended withdrawal periods in rats: different time courses of responding induced by cocaine cues versus cocaine priming over the first 6 months. Psychopharmacology 176:101-108.

Merikangas KR, Stolar M, Stevens DE, Goulet J, Preisig MA, Fenton B, Zhang H, O’Malley SS, Rounsaville BJ (1998) Familial transmission of substance use disorders. Arch Gen Psychiatry 55:973-979.

Nurnberger Jr JI, Wiegand R, Bucholz K, O’Connor S, Meyer ET, Reich T, Rice J, Schuckit M, King L, Petti T, Bierut L, Hinrichs AL, Kuperman S, Hesselbrock V, Porjesz B (2004) A family study of alcohol dependence: coaggregation of multiple disorders in relatives of alcohol-dependent probands. Arch Gen Psychiatry 61:1246-1256.

O'Brien CP (2005) Anticraving medications for relapse prevention: a possible new class of psychoactive medications. Am J Psychiatry 162:1423-1431.

Olausson P, Ericson M, Lof E, Engel JA, Soderpalm B (2001) Nicotineinduced behavioral disinhibition and ethanol preference correlate after repeated nicotine treatment. Eur J Pharmacol 417:117-123.

Olausson P, Jentsch JD, Taylor JR (2004) Nicotine enhances responding with conditioned reinforcement. Psychopharmacology 171:173-178.

Piazza PV, Deroche-Gamonent V, Rouge-Pont F, Le Moal M (2000) Vertical shifts in self-administration dose-response functions predict a drugvulnerable phenotype predisposed to addiction. J Neurosci 20:4226-4232.

Picciotto MR, Corrigall WA (2002) Neuronal systems underlying behaviors related to nicotine addiction: neural circuits and molecular genetics. J Neurosci 22:3338-3341.

Roberts DC, Brebner K (2000) GABA modulation of cocaine selfadministration. Ann NY Acad Sci 909:145-158.

Roberts DC, Koob GF, Klonoff P, Fibiger HC (1980) Extinction and recovery of cocaine self-administration following 6-hydroxydopamine lesions of the nucleus accumbens. Pharmacol Biochem Behav 12:781-787.

Rose JE, Corrigall WA (1997) Nicotine self-administration in animals and humans: similarities and differences. Psychopharmacology 130:28-40.

Shaham Y, Adamson LK, Grocki S, Corrigall WA (1997) Reinstatement and spontaneous recovery of nicotine-seeking in rats. Psychopharmacology 130:396-403.
Shaham Y, Shalev U, Lu L, De Wit H, Stewart J (2003) The reinstatement model of drug relapse: history, methodology and major findings. Psychopharmacology 168:3-20.

Shalev U, Grimm JW, Shaham Y (2002) Neurobiology of relapse to heroin and cocaine seeking: a review. Pharmacol Rev 54:1-42.

Shoaib M, Schindler CW, Goldberg SR (1997) Nicotine self-administration in rats: strain and nicotine pre-exposure effects on acquisition. Psychopharmacology 129:35-43.

Soderpalm B, Ericson M, Olausson P, Blomqvist O, Engel JA (2000) Nicotinic mechanisms involved in the dopamine activating and reinforcing properties of ethanol. Behav Brain Res 113:85-96.

Stewart J (2000) Pathways to relapse: the neurobiology of drug- and stressinduced relapse to drug-taking. J Psychiatry Neurosci 25:125-136.

Stewart J, de Wit H, Eikelboom R (1984) Role of unconditioned and conditioned drug effects in the self-administration of opiates and stimulants. Psychol Rev 91:251-268.

Stewart RB, Russell RN, Lumeng L, Li TK, Murphy JM (1994) Consumption of sweet, salty, sour, and bitter solutions by selectively bred alcoholpreferring and alcohol-nonpreferring lines of rats. Alcohol Clin Exp Res 18:375-381.

Swan GE, Carmelli D, Cardon LR (1997) Heavy consumption of cigarettes, alcohol and coffee in male twins. J Stud Alcohol 58:182-190.

True WR, Xian H, Scherrer JF, Madden PA, Bucholz KK, Heath AC, Eisen SA, Lyons MJ, Goldberg J, Tsuang M (1999) Common genetic vulnerability for nicotine and alcohol dependence in men. Arch Gen Psychiatry $56: 655-661$.

Tyndale RF (2003) Genetics of alcohol and tobacco use in humans. Ann Med 35:94-121.

Uhl GR, Liu QR, Naiman D (2002) Substance abuse vulnerability loci: converging genome scanning data. Trends Genet 18:420-425.

Vanderschuren LJ, Everitt BJ (2004) Drug seeking becomes compulsive after prolonged cocaine self-administration. Science 305:1017-1019.

Volkow ND, Fowler JS (2000) Addiction, a disease of compulsion and drive: involvement of the orbitofrontal cortex. Cereb Cortex 10:318-325.

Weiss F (2005) Neurobiology of craving, conditioned reward and relapse. Curr Opin Pharmacol 5:9-19.

Wise RA (1978) Catecholamine theories of reward: a critical review. Brain Res 152:215-247.

Wise RA (1996) Addictive drugs and brain stimulation reward. Annu Rev Neurosci 19:319-340.

Wise RA (2004) Dopamine, learning and motivation. Nat Rev Neurosci 5:483-494.

Yokel RA (1987) Intravenous self-administration: response rates, the effects of pharmacological challenges, and drug preference. In: Methods of assessing the reinforcing properties of abused drugs (Bozarth MA, ed), pp 1-34. New York: Springer. 